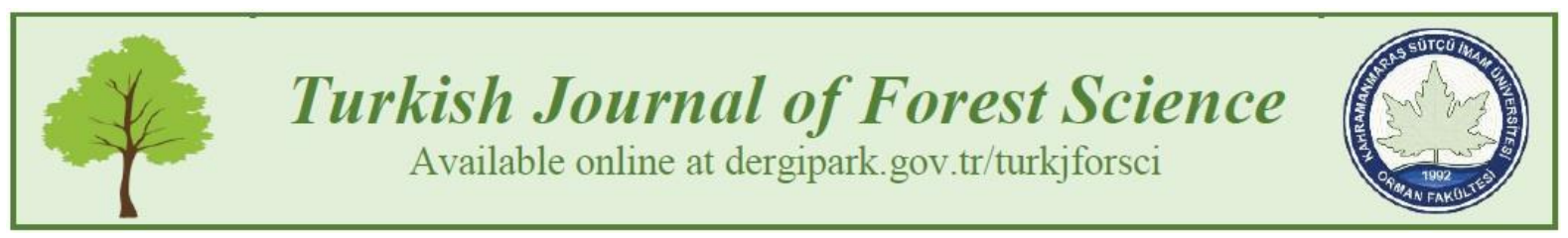

\title{
BAZI KAVAK (POPULUS L.) TAKSONLARININ KADMIYUMA KARŞI FITOEKSTRAKSIYON ROLLERI
}

\author{
Esra Nurten YER ÇELIKK ${ }^{1,}{ }^{*}$, Sezgin AYAN ${ }^{1}$, Mehmet Cengiz BALOGLU ${ }^{2}$ \\ ${ }^{1}$ Kastamonu Üniversitesi, Orman Fakültesi, Orman Mühendisliği Bölümü, Kastamonu \\ ${ }^{2}$ Kastamonu Üniversitesi, Mühendislik ve Mimarlık Fakültesi, Genetik ve Biyomühendislik Bölümü, \\ Kastamonu \\ *Sorumlu yazar: esranurtenyer@gmail.com
}

Esra Nurten YER ÇELIK: https://orcid.org/0000-0002-6368-3916

Sezgin AYAN: https://orcid.org/0000-0001-8077-0512

Mehmet Cengiz BALOĞLU: https://orcid.org/0000-0003-2976-7224

Please cite this article as: Yer Çelik, E. N., Ayan, S., Baloğlu, C. M. (2021). Bazı kavak (Populus L.) taksonlarının kadmiyuma karşı fitoekstraksiyon roller, Turkish Journal of Forest Science, 5(1), 46-56

\section{ESER BILGISI / ARTICLE INFO}

Araştırma Makalesi / Research Article

Geliş 10 Kasım 2020 / Received 10 November 2020

Düzeltmelerin gelişi 18 Ocak 2021 / Received in revised form 18 January 2021

Kabul 27 Ocak 2021 / Accepted 27 January 2021

Yayımlanma 30 Nisan 2021 / Published online 30 April 2021

ÖZET: Kadmiyum (Cd) ile kontamine olmuş toprakların 1slah başarısı; dokularına Cd birikmesine izin veren bitkilerin seçimine ve kullanımına bağlıdır. Kavak taksonlarının hızlı büyüme, derin kök sistemlerine sahip olma ve kısa rotasyonla işletilebilme özellikleri yeşil sslah için kullanılmalarına olanak sağlamaktadır. Bu araştırmada; altı kavak taksonu/klonu araştırmaya obje olmuştur. Bunlar; Populus alba L. (Akkavak), P. tremula L. (Titrek kavak), P. nigra L. (Karakavak) klon: Geyve ve N03.368A ve melez kavak klonları P. euramericana Dode. Guinier I-214 ve P. deltoides Bartr / Samsun (I-77/51). Kavak taksonlarının yaprak, kök ve dal aksamlarında Cd birikme miktarları Atomik Absorpsiyon Spektrometresi (AAS) cihazı ile belirlenmiştir. Araştırmacılar Cd birikimi yapan bitki dokularını; en çok biriken aksamdan en az birikim yapan doku kısmına doğru; kök> gövde $>$ yapraklar $>$ meyve $>$ tohum olarak sıralamaktadır. Çalışma kapsamında; yaprak örneklerinin analizi sonucunda; P. tremula'da 12,45 ppm miktarında en yüksek Cd miktarı tespit edilirken, minimum kadmiyum birikimi, $0,84 \mathrm{ppm}$ ile P. alba türlerinde tespit edilmiştir. Kök örneklerinin analizinde; en yüksek kadmiyum miktarı 34 ppm miktarıyla P. euramericana I-214'te, en düşük birikim miktarı ise P. alba türünde 4.6 ppm olarak saptanmıştır. Dal örneklerinde ise; en yüksek kadmiyum miktarı 5,54 ppm ile P. deltoides Samsun (I-77/51) klonunda bulunmuştur. Minimum kadmiyum birikimi ise, P. nigra Geyve klonunda $0.44 \mathrm{ppm}$ seviyesinde belirlenmiştir. Ayrıca araştırma sonucuna göre; Kavak taksonlarında sırasıyla en yüksek Cd birikimi yapan dokuların kök, dal ve yaprak olduğu tespit edilmiştir.

Anahtar kelimeler: Fitoremediasyon, Ağır metal, Hiperakümülatör, Yeşil Islah, AAS 


\title{
PHYTOEXTRACTION ROLES OF SOME POPLAR (POPULUS L.) TAXA AGAINST TO CADMIUM
}

\begin{abstract}
Reclamation success of soils contaminated with cadmium (Cd); It depends on the choice and use of plants that allow the accumulation of $\mathrm{Cd}$ to their tissues. The rapid growth of poplar taxa, having deep root systems and being able to operate with short rotation allow them to be used for green breeding. In this study, six poplar taxa were used. They were; P. alba (white poplar), P. tremula (aspen), P. nigra (black poplar) clone: Geyve and N03.368A and hybrid poplar clones; Populus euramericana Dode. Guinier / I-214 and Populus deltoides are Bartr / Samsun (I-77/51). The amount of Cd accumulation in leaf, root and branch parts of poplar taxa was determined by Atomic Absorption Spectrometer (AAS) device. Researchers plant tissues that accumulate $\mathrm{Cd}$; From the most accumulated component to by the least accumulated that as have a respectively; have been listed as root> stem> leaves $>$ fruit $>$ seed. This scope of; as a result of the analysis of leaf tissue samples; the highest amount of cadmium was determined in Populus tremula L. with $12.45 \mathrm{ppm}$. Minimum cadmium accumulation was determined in Populus alba L. poplar species in the amount of $0.84 \mathrm{ppm}$. As a result of the analysis of root tissue samples; the highest amount of cadmium was determined in I-214 with $34 \mathrm{ppm}$. Minimum cadmium accumulation was determined in Populus alba L. poplar species in an amount of $4.6 \mathrm{ppm}$. As a result of the analysis of branch tissue samples; the highest cadmium amount was found in Samsun (I-77/51) clone with an amount of $5.54 \mathrm{ppm}$. The minimum cadmium accumulation was determined at Populus nigra L. - Geyve poplar clone at a level of $0.44 \mathrm{ppm}$. Also; according to the results of the research; It was determined that the tissues with the highest $\mathrm{Cd}$ accumulation in poplar taxa, respectively, are roots, branches and leaves.
\end{abstract}

Keywords: Phytoremediation, Heavy metal, Hyperacommutator, Green breeding, AAS

\section{GíRIș}

Ağır metaller, yoğunluğu $>5 \mathrm{~g} / \mathrm{cm} 3$ veya atom ağırlığ $1 \geq 50$ olan elementler, $-\mathrm{Cu}, \mathrm{Fe}, \mathrm{Zn}, \mathrm{Pb}$, $\mathrm{Hg}, \mathrm{Co}, \mathrm{Cr}$, Ni ve Cd gibi- yer kabuğunda doğal olarak bulunan bileşiklerdir, bozulmaz ve yok edilemezler. Vücuda gidalar, içme suyu ve hava yolu ile girebilmektedirler. İz elementler gibi bazı ağır metaller $(\mathrm{Cu}, \mathrm{Se}, \mathrm{Zn})$ insan vücudunun metabolizmasını sürdürmek için gereklidirler. Bununla birlikte; yüksek konsantrasyonlarda toksik olabilirler ve zehirlenmelere yol açabilirler (Hamutoğlu ve ark., 2012).

Biyosferde aşırı konsantrasyonlarda As, Cd, Cr, Zn gibi ağır metallerin birikmesi çevresel kirlenmeye yol açmaktadır. Ortamdaki birçok metalin aşırı yoğun konsantrasyonları bitkiler ve hayvanlar tarafından kolayca emilebilmektedir ve bu nedenle besin zincirine girerek insanları tehdit edebilmektedir. Kadmiyum çeşitli endüstriyel faaliyetlerde sıklıkla kullanılmakta olan çevresel ve mesleki açıdan önemli bir ağır metaldir (Schulze ve ark., 2005; White ve Brown, 2010).

Son birkaç on yılda, kirlenmiş ortamlardan tehlikeli kirleticileri çıkarmak, imha etmek veya elimine etmek için bitkilerin kullanılmasına dayanan bitki ıslahı yöntemleri gibi yenilikçi, çevre dostu ve uygun maliyetli biyolojik teknolojilere odaklanılmıştır. Çevreyi temizlemek için bitkilerin kullanılması, kirlenmiş toprakların ve suların fitoremediasyonunda uygulanabilen etkili ve yerinde bir teknolojidir (Clemens ve ark., 2002; Schulze ve ark., 2005). Ancak, 
fitoremediasyon tekniği çok ağır düzeylerde kirlenmiş alanlarda değil, düşük düzeylerde kirlenmiş alanlarda bitkilerin kullanımına imkân vermektedir (Hamutoğlu vd. 2012). Fitoremediasyonun başarısı için kullanılan bitkilerin üç kriteri yerine getirmesi gereklidir. $\mathrm{Bu}$ kriterler; 1) Bu bitki kökleri topraktaki ağır metalleri alarak tüketebilmelidir, 2) Bu bitkiler ağır metalleri sürgünlere taşıyıp, biriktirmeli ve hasat sonrası bu sürgünler işlenebilmelidir, 3) Bitkiler, ağır metallerin yüksek konsantarasyonlarının toksik etkisinden kendi bünyelerini koruyacak mekanizmalara sahip olmalıdırlar (Gumaelius, 2004; Ayan ve Yer, 2017).

Toprakta $\mathrm{Cd}$ birikimi insan sağlığ için ciddi bir tehdit oluşturmaktadır. Bu birikimi azaltmak için çeşitli teknolojiler geliştirilmiştir. $\mathrm{Cd}$ ile kontamine olmuş toprakların fitoremediasyonunun başarısı, dokularında yüksek miktarda $\mathrm{Cd}$ biriktirebilen bitkilerin seçimi ve kullanımına bağlıdır. Kavak taksonları fitoremediasyon uygulamalarında tercih edilen türler arasındadır. Kavakların biyoremediasyon amaciyla kullanılması, yere derinlemesine nüfuz eden derin ve zengin kökleri sistemleri nedeniyle iyi sonuçlar vermektedir.

Kavak türleri hızlı büyüme özellikleri ve kısa rotasyon ile işletilebilmeleri nedeniyle ayrıca önem arz etmektedirler. Genellikle, Cd bitkilerin köklerinde depolanmaktadır. Bazı araştırmacılar, bitkinin meyve kısmında hiç Cd gözlemlemediğini bildirmiştir. Bitkinin farklı kısımlarında $\mathrm{Cd}$ birikimi azalan sıra ile kök> gövde $>$ yapraklar $>$ meyve $>$ tohum gerçekleşmektedir (Hall, 2002; Benavides ve ark., 2005).

Cd potansiyel olarak toksik ağır bir metaldir. Bitki dokularında da birçok morfolojik, fizyolojik ve genetik problemlere sebep olmaktadır. Bitki kökleri tarafından kirleticilerin alınımını ve sonrasında toprak üstü organlarda biriktirilmesini takiben bitkilerin hasat edilerek yok edilmesini içeren fitoekstraksiyon tekniği, $\mathrm{Cu}$ ve $\mathrm{Zn}$ gibi aktif olarak alınan besin elementleri ile $\mathrm{Cd}, \mathrm{Ni}$ ve $\mathrm{Pb}$ gibi besin elementi olmayan ağır metallerin uzaklaştırılmasında da kullanilmaktadır (Padmavathiamma ve Loretta, 2007). Kavaklar, fitoekstraksiyon, fitostabilizasyon, fitdegredasyon ve fitovolatilizasyon gibi birçok fitoremediasyon tekniğinde (Vanlı, 2007; Aybar ve ark., 2015) en yaygın kullanılan odunsu taksonlardır. Örneğin; Bor (B), bitkilerin normal büyümeleri için gerekli bir besindir. Toprakta düşük miktarda bulunmasına rağmen, özellikle kurak ve yarı kurak ortamlarda bitkiler için son derece toksik olmaktadır. Kavakların B toksisitesi ve birikimine toleranslı türler olduğu bilinmektedir. Bor (B) toksisitesi dünyada genişleyen bir çevre sorunu olduğundan yapay sulak alanlarda kavak türlerinin B uzaklaştırma performansının araştırıldığı bir çalışmada; Test edilen söğüt ve kavak türlerinin, toprağın filtreleme kapasitesini arttırarak, rizosfer çevresinde borun fitostabilizasyonunu sağladığı görülmüştür. B kaldırma yetenekleri açısından ise, Salix alba, Popolus alba ve S. babylonica yapay sulak alanlarda daha fazla bitki stabilizasyon performansina sahipken, Populus nigra ve Salix anatolica en yüksek fitoekstraksiyon ile B kaldırma kapasitesine sahiptir (Velioğlu ve ark., 2020).

Bu çalışmada; farklı kavak takson ve klonları ile bitkinin farklı aksamlarının Cd birikimleri karşılaştırmalı olarak ortaya konulmaya çalışılmıştır.

\section{MATERYAL VE YÖNTEM}

\section{Klonların Yetiştirilmesi ve Kadmiyum Stresinin Uygulanmast}

Ankara Behiçbey Orman Fidanlığı kavak klon kolleksiyonlarından temin edilen farklı kavak takson ve klonları bu çalışmada araştırma materyali olarak seçilmiştir. Araştırmada; Populus 
alba L. (Akkavak), P. tremula L. (Titrek kavak), P. nigra L. (Karakavak) klon: Geyve ve N03.368A ve P. euramericana Dode. Guinier / I-214 (Melez kavak) ve P. deltoides Bartr. I Samsun (77/51) tür ve klonları kullanılmıştır.

Fidan üretimi için sert çelik kullanılmıştır. Çelik materyalleri yaklaşık 15-20 cm uzunluğunda ve $12 \pm 2 \mathrm{~mm}$ kalınlığında hazırlanmıştır. Çeliklerde yeterli sayıda nod (En az 2-3) bulunmasına dikkat edilmiştir. Çelikler dikim öncesinde 5-10 saniye kadar steril su ile seyreltilmiş sıvı bitki hormonuna [indol-3-butirik asit (IBA), fungisit, borik asit, Farmatalk-8000 ppm] maruz bırakılmıştır. Çelikler, hormon uygulamasından sonra 1:3 oranında turba : perlit karışımı içeren $25 \times 40 \mathrm{~cm}$ polietilen torbalara dikilmişlerdir. Oluşan sürgünler $80-100 \mathrm{~cm}$ boya ulaştığında $\mathrm{Cd}$ stresi uygulanmıştır. Stres uygulaması, günün serin saatlerinde toprak nem seviyesi göz önüne alınarak, bitkilere günlük $200 \mathrm{mM} \mathrm{CdSO} \mathrm{H}_{2} \mathrm{O}$ çözeltisinin (He ve ark., 2013; Baccioa ve ark., 2014) uygulanması ile gerçekleştirilmiştir. Kadmiyum stresi uygulanmış kavak türleri/klonları, fidan torbalarının ağırlıklarına göre sırasıyla 100-250 ml CdSO${ }_{4} \mathrm{H}_{2} \mathrm{O}$ çözeltisi ile kontrol grubu ise su ile muamele edilmiştir. Stres uygulaması başladıktan sonraki 28. günde gerek $\mathrm{Cd}$ uygulaması yapılmış gerekse kontrol fidanlarının yaprak, dal ve kök aksamlarından örnekler alınmıştır.

\section{Atomik Absorpsiyon Spektrometresi (AAS) ile Kavak Dokularında Kadmiyum Birikiminin Ölçülmesi}

Cd ağır metal stresine maruz bırakılan ve kontrol grubundaki kavak taksonlarından yaprak, kök ve dal örnekleri alınarak laboratuvar ortamında 3 gün boyunca $70{ }^{\circ} \mathrm{C}$ 'de kurutulmuştur (Marmiroli ve ark., 2013). Kurutulan örnekler blender yardımıyla ve havanda ezilerek homojenize edilmiştir. Örnekler 3 tekrarlı 0,5 gr tartılmıştır. Örnekler üzerine çeker ocak içerisinde 1:4 oranında $\mathrm{HNO}_{3}$ ve \% 70'lik perklorik asit $\left(\mathrm{HCIO}_{4}\right)$ karışımından $6 \mathrm{ml}(1 \mathrm{gr}=12$ $\mathrm{ml}$ ) ilave edilmiştir (Twyman, 2005).

Asit ile muamele edilen örnekler kapalı sistem yakma cihazında (Milestone-Ethos One-1.600 Watt) cihaza ait özel kaplar içerisinde yaklaşık 1 saat bekletilmiştir. Ölçümler, "Atomik Absorbsiyon Spektroskopi (AAS)" cihazı ile yapılmıştır. Kavak klonlarına ait yaprak ve dal örneklerinde ölçümleri ng/mL (ppb) seviyesinde hassas ölçüm yapabilen "Grafit Fırın Sistem" tekniği ile çalışan GBC, Avanta marka AAS cihazı ile saptanmıştır. Kök örneklerinde ise değerlerin okumas $\mu \mathrm{g} / \mathrm{mL}$ (ppm) seviyesinde "Alevli Atomik Absorbsiyon" tekniği ile çalışan AAS cihazı ile gerçekleştirilmiştir.

Cd ölçümleri 228,8 nm lamba dalga boyunda yapılmıştır. Örnekler için 3 farklı standartlar hazırlanmıştır. Standart hazırlanışı: 1 gr metalik kadmiyum tartılır ve 1 lt'lik balon jojeye aktarılır. Üzerine yaklaşık $30 \mathrm{ml} \mathrm{HCI}$ eklenir ve hacim çizgisine kadar deiyonize saf su ile tamamlanır. Bu şekilde 1000 ppm'lik Cd standardı hazırlanmıştır. Kök doku örneklerinde $0.200,1.000,2.000 \mu \mathrm{g} / \mathrm{ml}$ (ppm), dal doku örnekleri için 20.000, 50.000, $100.000 \mathrm{ng} / \mathrm{ml}$ (ppb) ve yaprak doku örnekleri için 10.000, 25.000, $50.000 \mathrm{ng} / \mathrm{ml}$ (ppb) standart çözeltileri hazırlanmıştır.

Standartların dalga boyunda okuduğu absorbanlardan faydalanarak konsantrasyonlara karşı absorban grafiği çizdirilmiş ve bir standart eğri oluşturulmuştur. Cihaz örneğin absorbansını okuduğunda kalibrasyon grafiğinden konsantrasyon ölçmüştür. 
Cd miktarı $(\mathrm{mg} / \mathrm{kg})=(\mathrm{Cö} \times \mathrm{V}$ x SF $) / \mathrm{m}$ hesaplamasına bağlı kalınarak belirlenmiştir. Cö= Standart eğrisinden yararlanarak okunan konsantrasyon, $V=$ yakma işlemi sonrası örneğin konulduğu balonjojenin hacmi $(\mathrm{ml}), \mathrm{m}=$ alınan örnek miktarı $(\mathrm{g}), \mathrm{SF}=$ Seyreltme faktörü. Örneğin; $C \ddot{0}=10,731, \mathrm{~V}=50 \mathrm{SF}=1 \mathrm{~m}=0,5$ ise $\mathrm{Cd}$ miktarı = 1073, $1 \mathrm{ppb}(\mathrm{ng} / \mathrm{ml}) ; \mathrm{ppm}$ seviyesinde 1,073 ppm okuması yapılmıştır ve örnek konsantrasyon değeri olarak alınmıştır ( 1 ppm =1000 $\mathrm{ppb})$.

Ölçümler cihaz sisteminde bir örnek için 3 tekrar ve her tekrar için 5 kez okuma değeri alınmıştır. Ortalama hesabına bağlı kalınarak kontrol ve stres uygulanan kavak dokularında (yaprak, dal ve kök) kadmiyum birikimine ait hesaplama kullanılarak saptanmıştır.

\section{Istatistik Analizler}

Kavak türleri/klonları ile bitki aksamları (kök, dal, yaprak) arasındaki Cd birikim düzeyi farklılığını belirlemek için SPSS programı (16. Versiyon) kullanılarak Varyans Analizi (ANOVA) uygulanmıştır. ANOVA sonuçları doğrultusunda, oluşan farklılıkların homojen grupları Tukey's testi ile test edilmiştir.

\section{BULGULAR}

Kavak takson ve klonlarına göre yaprak, kök ve dal aksamlarında biriken Cd miktarları Şekil 1'de gösterilmiştir. Kavak taksonları/klonları arasında kök, dal ve yaprak dokusunda Cd birikim miktarı bakımından anlamlı farklılıklar tespit edilmiştir. Taksonlar arasında belirlenen anlamlı farklılıklar ve çoklu test gruplandırmaları Tablo 1'de verilmiştir.

Tablo 1. Bitki aksamlarına göre taksonlar/klonlar arasındaki Cd birikim miktarları

\begin{tabular}{|c|c|c|c|c|}
\hline \multirow[b]{2}{*}{ Tür/Klon } & Kök (ppm) & Dal (ppm) & Yaprak (ppm) & \multirow{2}{*}{$\begin{array}{c}\text { Bitki aksamlarında Cd } \\
\text { birikim miktarları }\end{array}$} \\
\hline & \multicolumn{3}{|c|}{$\mathrm{Cd}$} & \\
\hline Populus nigra, Geyve & $6,10 \pm 0,0057 b$ & $0,44 \pm 0,0057 \mathrm{a}$ & $1,07 \pm 0,0057 b$ & Kök>Yaprak>Dal \\
\hline Populus nigra N. 03.368A & $14,60 \pm 0,0057 \mathrm{~d}$ & $3,55 \pm 0,0057 \mathrm{e}$ & $3,53 \pm 0,0088 \mathrm{e}$ & Kök>Dal>Y Yaprak \\
\hline Populus euroamericana I-214 & $33,95 \pm 0,0057 f$ & $3,20 \pm 0,0057 \mathrm{c}$ & $2,83 \pm 0,0057 d$ & Kök>Dal>Y Yaprak \\
\hline Populus tremula & $9,87 \pm 0,0057 \mathrm{c}$ & $3,49 \pm 0,0057 d$ & $12,45 \pm 0,0057 f$ & Yaprak>Kök>Dal \\
\hline Populus deltoides Samsun (77/51) & $27,75 \pm 0,0057 \mathrm{e}$ & $5,54 \pm 0,0057 f$ & $2,57 \pm 0,0057 \mathrm{c}$ & Kök>Dal>Y Yaprak \\
\hline Populus alba & $4,55 \pm 0,0057 \mathrm{a}$ & $1,33 \pm 0,0057 b$ & $0,83 \pm 0,0057 \mathrm{a}$ & Kök>Dal> Yaprak \\
\hline F değeri ve P düzeyi & $\begin{array}{l}459680,25 * \quad / \\
0,000\end{array}$ & $\begin{array}{l}98057,70 * / \\
0,000\end{array}$ & $128300,04 * / 0,000$ & \\
\hline
\end{tabular}

*: \% 95 güven düzeyini temsil eder. 


\section{Turkish Journal of Forest Science}

Available online at dergipark.gov.tr/turkjforsci

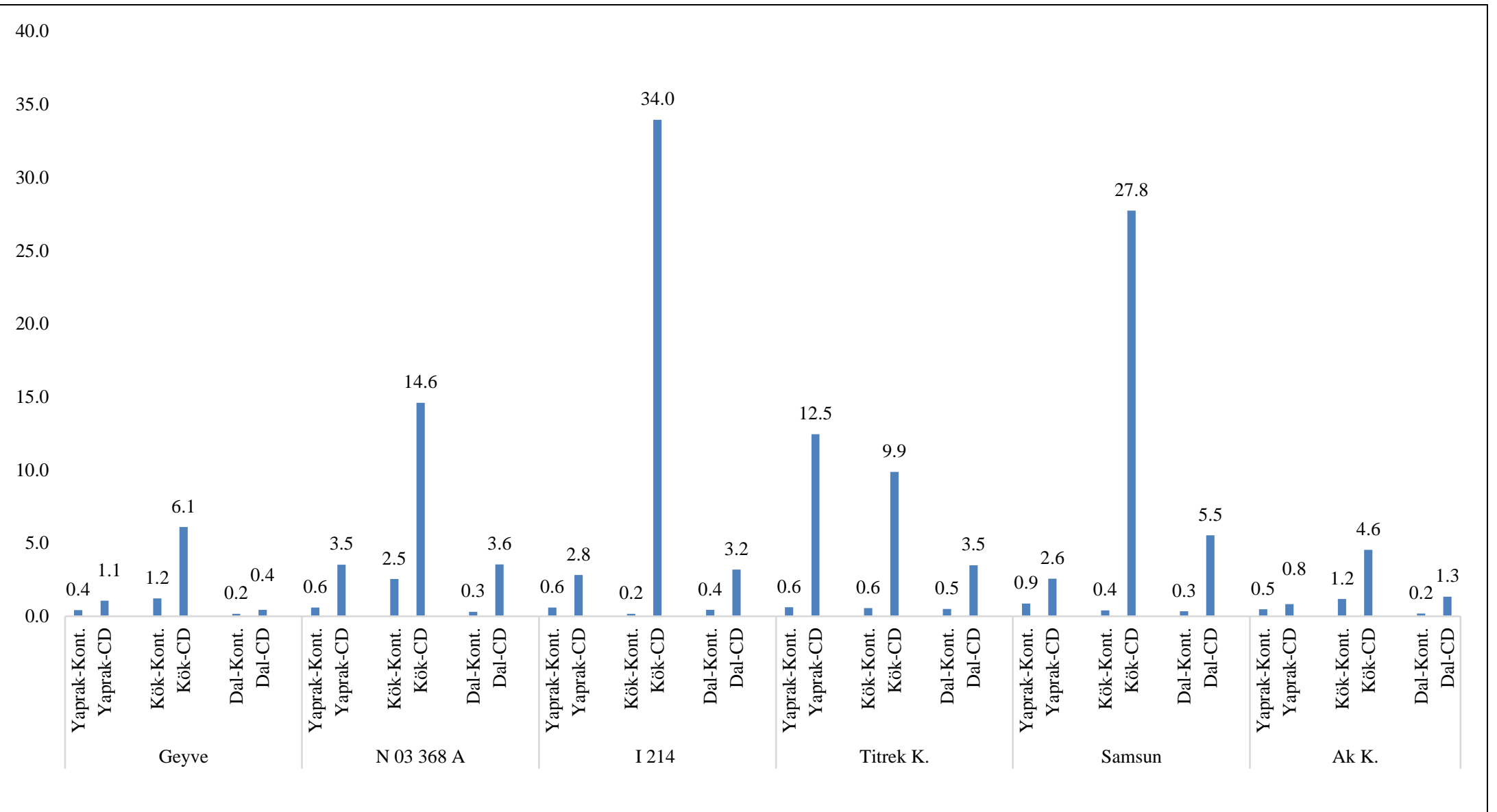

Şekil 1. Farklı kavak taksonlarının/klonlarının yaprak, kök ve dal dokularında Cd birikim miktarları 


\section{Turkish Journal of Forest Science \\ Available online at dergipark.gov.tr/turkjforsci}

Yaprak doku örneklerinin analizleri sonucunda; Cd miktarı en yüksek titrek kavakta 12,45 ppm düzeyinde tespit edilmiştir. En az kadmiyum birikimi ise 0,84 ppm düzeyinde akkavak türünde belirlenmiştir (Şekil 2). Taksonların yaprak örneklerindeki Cd birikimleri arasında 14,8 kat daha fazla fark tespit edilmiştir.

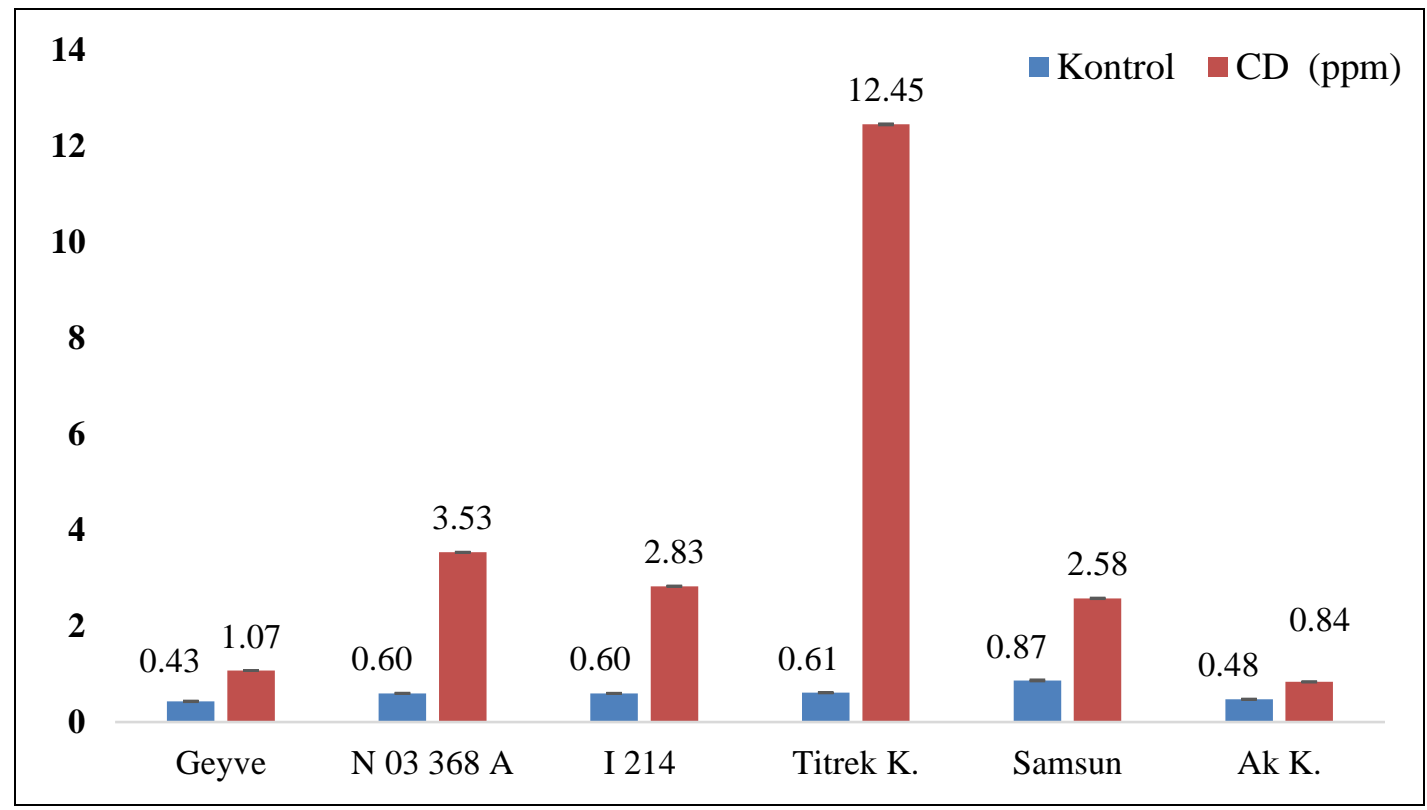

Şekil 2. Kavak taksonları yaprak örneklerinde kadmiyum birikim miktarları

Kök aksamlarının analizleri sonucunda; Cd miktarı en yüksek I-214 melez kavağında 34 ppm düzeyinde, en az birikim ise 4,6 ppm düzeyinde akkavak türünde belirlenmiştir (Şekil 3). Taksonların kök örneklerindeki Cd birikimleri arasında 7,4 kat daha fazla fark tespit edilmiştir.

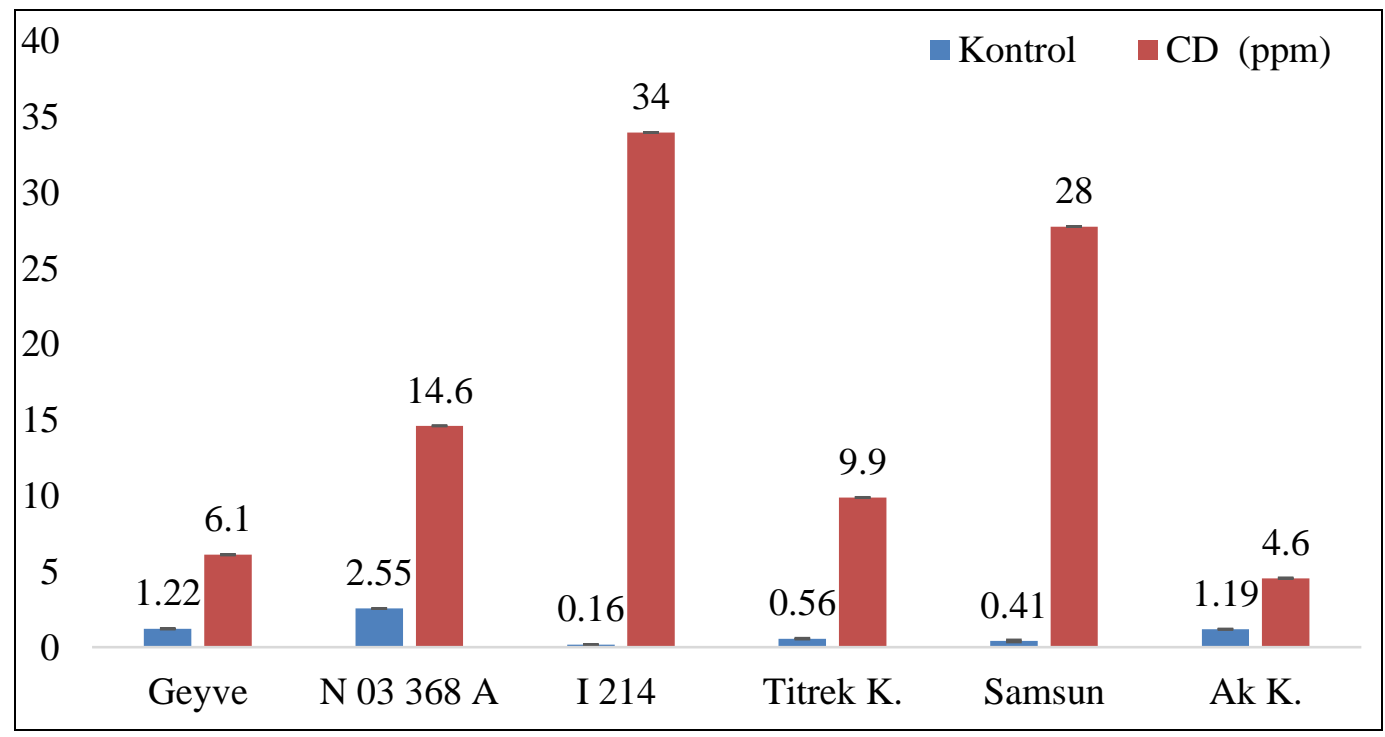

Şekil 3. Kavak taksonları kök örneklerinde kadmiyum birikim miktarları 
Dal örneklerinin analizlerinde ise Cd miktarı en yüksek $P$. deltoides Samsun (77/51) klonunda 5,54 ppm düzeyinde, en az Cd birikimi ise 0,44 ppm düzeyinde karakavak Geyve klonunda belirlenmiştir (Şekil 4). Taksonların dal örneklerindeki Cd birikimi açısından en yüksek ve en düşük miktar arasında 12,6 kat bir varyasyon tespit edilmiştir.

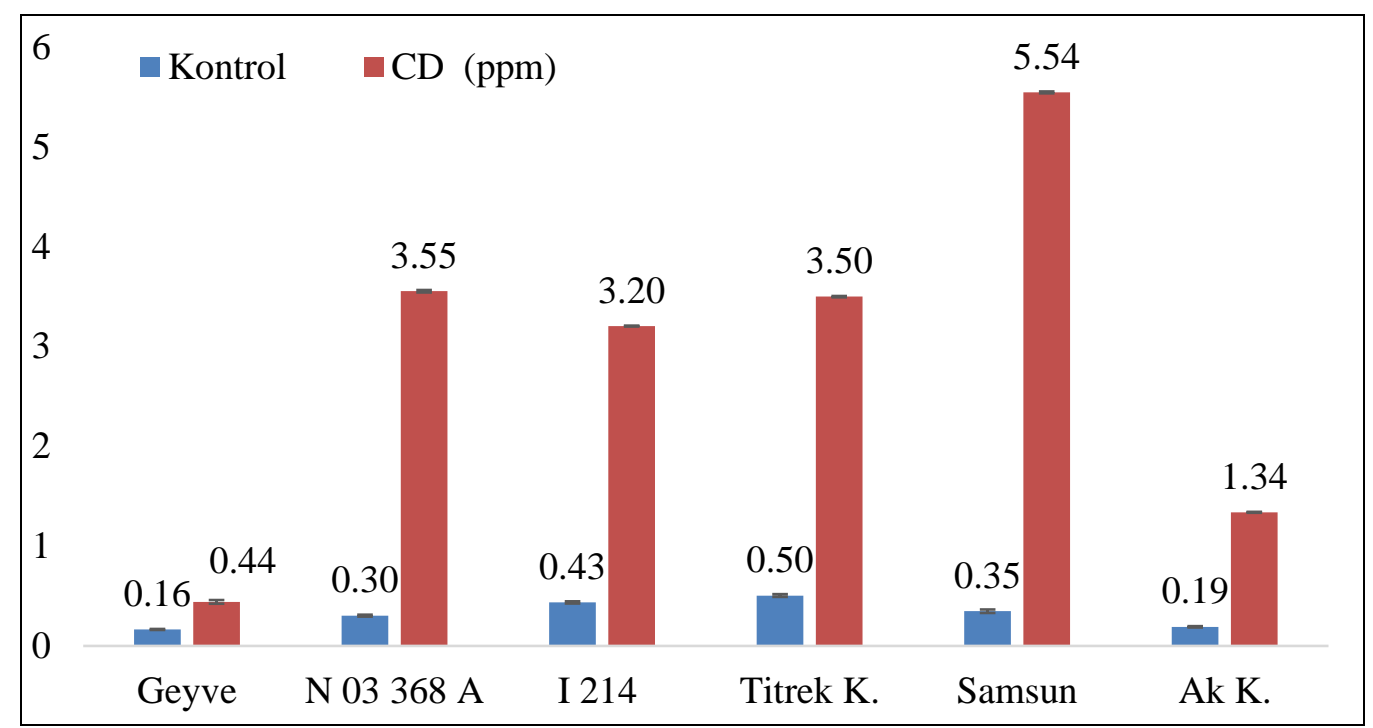

Şekil 4. Kavak taksonları dal örneklerinde kadmiyum birikim miktarları

\section{TARTIŞMA ve SONUÇ}

Topraktaki Cd birikimi insan sağlı̆̆ için ciddi bir tehdit oluşturmaktadır. Topraktaki Cd seviyesini azaltmak için çeşitli teknolojiler geliştirilmiştir. Bu teknolojilerden biri topraktaki $\mathrm{Cd}$ absorbe etmek için bitkilerin depo olarak kullanımı yani fitoremediasyondur. Yani, Cd depolayan bitkilerin hasat edilmesi ile toprağın temizlenmesidir. Cd ile kirlenmiş topraklarda fitoremediasyonun başarısı dokularında $\mathrm{Cd}$ birikmesine olanak sağlayacak bitkilerin seçimi çok önemlidir. Bu bakımdan, kavak taksonları fitoremediasyon için kullanımı önerilmektedir (Kramer, 2010). Çünkü, kavak ağacı türleri hızlı büyüme gösteren, derin kök sistemine ve kısa rotasyon ile işletilebilmeleri sebebiyle tercih edilmektedir (Di Lonardo vd., 2011). ABD'nin Güney Dakota eyaletinde hibrit bir kavak ile yürütülen çalışmada; Kavakların ilk yıl $12 \mathrm{~m}$ büyüme kaydederek, bünyesinde tahmin edilenden çok daha yüksek miktarlarda As ve $\mathrm{Cd}$ biriktirmiştir (Pivetz, 2001). Cd'un Populus tremula x Populus alba (genotip INRA 7171B4)'daki kumülatif etkilerini ortaya koymak için yürütülen ardışık iki Cd konsantrasyonu (3.2 mmol ve 16 mmoles Cd) uygulamasında; Kavağın fitoremediasyon ve özellikle de fitostabilizasyon için potansiyel bir bitki olabileceği vurgulanmıştır (Velioğlu ve Akgül, 2016).

Bu çalışmada; Atomik absorbsiyon cihazı yardımıyla kavak taksonlarının yaprak, kök ve dal aksamlarındaki kadmiyum birikim miktarı belirlenmiştir. Yaprak doku örneklerinin analizleri sonucunda; kadmiyum miktarı en yüksek $P$. tremula L.'da $12,45 \mathrm{ppm}$ düzeyinde tespit edilmiştir. En az kadmiyum birikimi ise $0,84 \mathrm{ppm}$ düzeyinde $P$. Alba kavak türünde belirlenmiştir. Kök doku örneklerinin analizleri sonucunda; kadmiyum miktarı en yüksek $P$. euramericana I-214 klonunda 34 ppm düzeyinde, en az kadmiyum birikimi ise 4,6 ppm düzeyinde $P$. alba kavak türünde belirlenmiştir. Dal doku örneklerinin analizleri sonucunda ise; kadmiyum miktarı en yüksek $P$. deltoides Samsun (77/51) klonunda 5,54 ppm düzeyinde, en az kadmiyum birikimi ise 0,44 ppm düzeyinde $P$. nigra - Geyve kavak klonunda belirlenmiştir. Yaprak döken türler için yaprak dokusunda kadmiyum birikiminin tahmini 
olarak ortalama 0.1 ile $17 \mathrm{ppm}$ arasında olabileceği belirlenmiştir. Akçaağaçta yaprak dokusunda 1.6 ppm, gövde/dal kısmında 4.9 ppm kadmiyum birikimi saptanmıştır. Söğüt bitkisinde ise yaprak dokusunda ortalama $15.7 \mathrm{ppm}$ ve gövde/dal kısminda $37.6 \mathrm{ppm}$ birikim olduğu tespit edilmiştir. Populus tremuloides Michx.'de ise yaprak aksamında 7.7 ve gövde/dal aksamında 13.7 olarak kadmiyum birikimi görülmüştür (Shacklette, 1972). Araştırmanın sonuçları, bu çalışmanın bulguları ile benzerlik göstermektedir.

Kavak taksonlarında en yüksek kadmiyum birikiminin görüldüğü dokunun kök olduğu tespit edilmiştir. Yaprak ve dal birikim düzeylerinden oldukça yüksek değerler kök dokusunda belirlenmiştir. Araştırıcılar çalışmalarında Kavak ağacının farklı dokularında biriken toplam $\mathrm{Cd}$ miktarının, otsu hiperakümülatörler tarafından biriktirilmiş $\mathrm{Cd}$ miktarından çok daha yüksek olduğunu tespit etmişlerdir (Di Lonardo ve ark., 2011; Pietrini ve ark., 2010). Bu sonuçlar, kavağın $\mathrm{Cd}$ fitoremediasyonu için uygun olduğunu göstermektedir. Ayrıca, birçok çalışmada kavağın kök, ağaç kabuğu ve yapraklarında farklı Cd birikimi, olduğunu tespit edilmiştir (Laureysens ve ark., 2005; He ve ark., 2011; Elobeid ve ark., 2012). Kadmiyum birikim miktarı farklı çalışmalarda da kök>gövde>yaprak>meyve>tohum şeklinde tespit edilmiştir (Benavides ve ark., 2005; Dai ve ark., 2013; Jakovljevic ve ark., 2014). Ayrıca, aynı kavak türün farklı klonlarının tür içi genetik farklılı̆̆ı nedeniyle ağır metal toleransının varyasyon gösterdiği vurgulanmıştır (Clemens, 2001; Castiglione ve ark., 2009). Bu araştırma kapsamında kullanılan altı farklı takson ve klonun tamamında dal ve yaprak aksamlarına göre en çok Cd birikimi kök aksamında tespit edilmiştir.

\section{YAZAR KATKILARI}

Yazarlar makaleye eşit oranda katkı sağlamış olduklarını beyan eder.

\section{TEŞEKKÜR}

Araştırma, Kastamonu Üniversitesi, Bilimsel Araştırma Projeleri Yönetim Birimi (Proje No: KÜBAP-01/2016-39) tarafindan desteklenmiştir. Bu çalışma Dr. Öğr. Üyesi Esra Nurten YER ÇELIK' 'in doktora tezinden üretilmiştir.

\section{KAYNAKLAR}

Aybar, M., Bilgin, A., Sağlam, B., (2015). Fitoremediasyon Yöntemi İle Topraktaki Ağır Metallerin Giderimi, Doğal Afetler ve Çevre Dergisi, 1 (1-2) 59-65.

Baccioa, D., Castagna, A., Tognetti, R., Ranieri, A., Sebastiani, L. (2014). Early responses to cadmium of two poplar clones that differ in stress tolerance. Journal of Plant Physiology, 171, 1693-1705.

Benavides, M. P., Gallego, S. M. (2005). Tomaro, M. L.. Cadmium Toxicity in Plants. Brazil Journal Plant Physiology, Vol.17 No.1, Londrina, 21-34.

Castiglione, S., Todeschini, V., Franchin, C., Torrigiani, P., Gastaldi, D., Cicatelli, A., Rinaudo, C., Berta, G., Biondi, S., Lingua, G. (2009). Clonal differences in survival capacity, copper and zinc accumulation, and correlation with leaf polyamine 
levels in poplar: A large-scale field trial on heavily polluted soil, Environ Pollut., 157:2108-2117.

Clemens, S. (2001). Molecular mechanisms of plant metal tolerance and homeostasis. Planta, 212:475-486 doi:10.1007/s004250000458.

Clemens, S., Palmgren, M.G. \& Krämer, U. (2002). A long way ahead: understanding and engineering plant metal accumulation. Trends in Plant Science, 7, 309-315.

Dai, Hui-Ping., Chan-Juan, Shan., Genliang, Jia., Chao, Lu., Tu-Xi Yang and An-Zhi Wei. (2013). Cadmium detoxification in Populus Xcanescens. Turkish Journal of Botany, 37: 950-955.

Di Lonardo, S., Capuana, M., Arnetoli, M., Gabbrielli, R., Gonnelli, C. (2011). Exploring the metal phytoremediation potential of three Populus alba L. clones using an in vitro screening. Environ Sci Pollut Res., 18:82-90.

Elobeid, M., Göbel, C., Feussner, I., Polle, A. (2012). Cadmium interferes with auxin physiology and lignification in poplar. J Exp Bot., doi :10.1093/jxb/err384.

Hall, J. L. (2002). Cellular mechanisms for heavy metal detoxification and tolerance. Journal of Experimental Botany, 53, 1-11.

Hamutoğlu, R., Dinçsoy, A.B., Cansaran-Duman, D., Aras, S., (2012). Biyosorpsiyon, adsorpsiyon ve fitoremediasyon yöntemleri ve uygulamaları, Türk Hijyen ve Deneysel Biyoloji Dergisi, 69(4): 235-53.

He, J., Li, H., Luo, J., Ma, C., Li, S., Qu, L., Gai, Y., Jiang, X., Janz, D., Polle, A., Tyree, M., Luo Z. (2013). A Transcriptomic Network Underlies Microstructural and Physiological Responses to Cadmium in Populus canescens L. Plant Physiology, Vol. 162, pp. 424-439.

He, J., Qin, J., Long, L., Ma, Y., Li, H., Li, K., Jiang, X., Liu, T., Polle, A., Liang, Z., Luo, Z. B. (2011). Net cadmium flux and accumulation reveal tissue-specific oxidative stress and detoxification in Populusxcanescens. Physiol Plant 143:50-63.

Jakovljevic, T., Bubalo, M. C., Orlovic, S., Sedak M., Bilandzic, N., Brozincevic, I., Redovnikovic IR. (2014). Adaptive response of poplar (Populus nigra L.) after prolonged $\mathrm{Cd}$ exposure period. Environmental science and pollution research international, 21:3792-3802 doi:10.1007/s11356-013-2292-7.

Kramer, U. (2010). Metal hyperaccumulation in plants. Annu Rev Plant Biol, 61:517-534.

Laureysens, I., De Temmerman, L., Hastir, T., Van Gysel, M., Ceulemans, R. (2005). Clonal variation in heavy metal accumulation and biomass production in a poplar coppice culture, II. Vertical distribution and phytoextraction potential, Environ Pollut., 133:541-551.

Marmiroli, M., Imperiale, D., Maestri, E., Marmiroli, N. (2013). The response of Populus spp. to cadmium stress: Chemical, morphological and proteomics study. Chemosphere, 93:1333-1344.

Padmavathiamma PK, Loretta YL. (2007). Phytoremediation technology: Hyper-accumulation metals in plants. Water Air Soil Pollut, 184: 105-26.

Pietrini, F., Zacchini, M., Iori, V., Pietrosanti, L., Bianconi, D., Massacci, A. (2010). Screening of poplar clones for cadmium phytoremediation using photosynthesis, biomass and cadmium content analyses, Int J Phytoremediat 12:105-120. Plant Physiology Preview. DOI:10.1104/pp.110.164152.

Pivetz, B. E. (2001). Phytoremediation of contaminated soil and ground water at hazardous waste sites, United States Environmental Protection Agency EPA, 540/S-01/500, 36 p.

Schulze, E., Beck, E., Müller-Hohenstein, K. (2005). Plant Ecology. Springer, Germany, Berlin, 702p.

Shacklette, H. T. (1972). Cadmium in plants. U.S. Geological Survey Bull. 1314-G. 
Twyman, R. M. (2005). Sample Dissolution for Elemental Analysis/Wet Digestion. pp: 45034510, University York, UK.

Vanlı, Ö. (2007). Pb, Cd, B Elementlerinin Topraklardan Şelat Destekli Fitoremediasyon Yöntemiyle Giderilmesi, İ.T.Ü Fen Bilimleri Enstitüsü, Çevre Mühendisliği Anabilim Dalı, 88 s. İstanbul.

Velioğlu, E., Akgül, S., (2016). Poplars and Willows in Turkey: Country Progress Report of the National Poplar Commision. Time period: 2012-2015, Poplar and Fast Growing Forest Trees Research Institute, 20. S, İzmit/Turkey.

White, P. J. ve Brown, P. H. (2010). Plant nutrition for sustainable development and global health. Annals of Botany, 105, 1073-1080. 